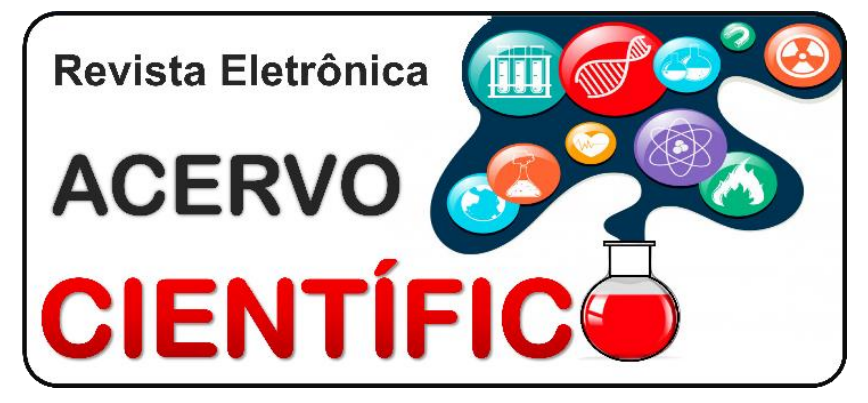

\section{REVISÃO BIBLIOGRÁFICA}

Recebido em: 7/2020

Aceito em: $8 / 2020$

Publicado em: 2/2021

\title{
Manejo e identificação de pacientes susceptíveis à hipertermia maligna: uma revisão bibliográfica
}

Management and identification of patients susceptible to malignant hyperthermia: a bibliographic review

\begin{abstract}
Manejo y identificación del paciente susceptible a la hipertermia maligna: una revisión bibliográfica
\end{abstract}

Tainara Sales Miranda ${ }^{1 *}$, Diego de Matos Silveira ${ }^{2}$, Adriana Dantas Amaro Pereira ${ }^{3}$, Ana Kelly Teixeira Rocha ${ }^{1}$, Filipe Gomes de Carvalho ${ }^{1}$, João Vitor Diniz Barreto ${ }^{3}$, Jorge Lacerda de Queiroz Oliveira $^{1}$, Letícia Meira Silveira ${ }^{1}$, Pedro Dias de Carvalho', Ramon Felipe Alves Teixeira'.

\begin{abstract}
Resumo: Este artigo buscou discutir a importância da identificação e do manejo precoce da crise de hipertermia maligna (HM), bem como a necessidade de investigação genética, em especial das famílias em que já foram relatados casos da doença. A hipertermia maligna é uma desordem genética hereditária desencadeada pelo uso de anestésicos inalatórios halogenados e/ou pelo agente bloqueador neuromuscular despolarizante succinilcolina, usados em anestesia geral. É imprescindível o conhecimento técnico-científico e a ação imediata da equipe médica durante a crise de HM, uma vez que a menor taxa de morbimortalidade dos pacientes é dependente de um rápido manejo da crise. $O$ trabalho trata-se de uma revisão bibliográfica sobre a gravidade da condição da HM com enfoque no diagnóstico laboratorial e clínico para a identificação de pacientes susceptíveis à $\mathrm{HM}$ e no manejo da crise, cujo teste padrão ouro para a confirmação da doença é o teste de contratura muscular in vitro com halotano-cafeína e o principal tratamento utilizado para a reversão da crise é o dantrolene.
\end{abstract}

Palavras-chave: Hipertermia maligna, Anestesia, Suscetibilidade.

\begin{abstract}
This article aims to discuss the importance of the identification and early management of the malignant hyperthermia $(\mathrm{MH})$ crisis, as well as the need for genetic investigation, especially of families in which cases of the disease have already been reported. Malignant hyperthermia is an inherited genetic disorder triggered by the use of halogenated inhalational anesthetics and/or the depolarizing neuromuscular blocking agent succinylcholine, used in general anesthesia. Technical-scientific knowledge and immediate action by the medical team during the $\mathrm{MH}$ crisis is essential, since the lower morbidity and mortality rate of patients is dependent on a quick crisis' management. This work is a bibliographic review about the severity of the
\end{abstract}

\footnotetext{
${ }^{1}$ Centro Universitário de Caratinga (UNEC), Caratinga - MG. *E-mail: tainarasmiranda@hotmail.com

2Universidade Federal de Juiz de Fora (UFJF), Juiz de Fora - MG.

${ }^{3}$ Universidade de Vassouras (UV), Vassouras - RJ.
} 
condition of $\mathrm{MH}$ with a focus on laboratory and clinical diagnosis for the identification of patients susceptible to $\mathrm{MH}$ and in the management of the crisis, in which the gold standard test for the confirmation of the disease is the muscle contraction in vitro with halothane-caffeine and the main treatment used to reverse the crisis is dantrolene.

Keywords: Malignant hyperthermia, Anesthesia, Susceptibility.

Resumen: Este artículo pretende discutir laimportancia de laidentificación y el manejo temprano de lacrisis de hipertermia maligna (HM), así como lanecesidad de investigación genética, especialmente de familiasenlas que ya se han reportado casos de laenfermedad. La hipertermia maligna es untrastorno genético hereditariodesencadenado por el uso de anestésicos inhalados halogenados y/o el agente de bloqueo neuromuscular despolarizante succinilcolina, utilizado en anestesia general. El conocimiento técnico-científico y laaccióninmediatadel equipo médico durante lacrisis de HM es esencial, ya que latasa más baja de morbilidad y mortalidad de los pacientes depende del manejo rápido de lacrisis. El trabajo es una revisión bibliográfica sobre lagravedad de lacondición de HM conun enfoque enel diagnóstico clínico y de laboratorio para laidentificación de pacientes susceptibles a HM y enel manejo de lacrisis, cuyapruebaestándar de oro para laconfirmación de laenfermedad es La contracción muscular in vitro conhalotano-cafeína y eltratamiento principal utilizado para revertirlacrisis es eldantroleno.

Palabras clave: Hipertermia maligna, Anestesia, Susceptibilidad.

\section{INTRODUÇÃO}

A hipertermia maligna (HM) é uma síndrome hipermetabólica grave, de origem genética e hereditária, desencadeada pelo uso de anestésicos inalatórios halogenados e/ou pelo agente bloqueador neuromuscular despolarizante succinilcolina, usados em anestesia geral (SILVA HCA, et al., 2018).

Quanto ao mecanismo fisiopatológico dessa doença, é uma desordem farmacogenética potencialmente fatal que afeta indivíduos predispostos, sendo desencadeada por uma canalopatia que interfere na liberação de cálcio, além de ser uma doença de herança autossômica dominante com penetrância variável (CORVETTO MA, et al., 2013; NUNES RBS, et al., 2020).

A síndrome tem como principais sinais e sintomas: taquicardia, taquipneia, hipercarbia, hipertermia, rigidez muscular, rabdomiólise, acidose, instabilidade hemodinâmica e insuficiência de múltiplos órgãos. Contudo, as apresentações clínicas são variáveis, sendo desde formas fulminantes, passando por apresentações frustras, atípicas ou formas mais brandas com apenas o espasmo de masseter isolado (SILVA HCA, et al., 2019; COSTA WP, et al., 2017).

De acordo com Dagestad A e Hermann M (2017), a HM tem uma taxa de ocorrência que varia de 1 em 3.000 a 1 em 50.000 procedimentos com o uso de anestésicos gerais. Os casos são mais comuns em crianças enquanto que os indivíduos adultos são menos acometidos, sendo que mais de $50 \%$ dos casos ocorrem em pacientes com menos de 15 anos.

Em relação ao diagnóstico da HM, é necessário ressaltar a importância do histórico familiar do paciente que será submetido ao processo anestésico. Em virtude desta condição constituir uma desordem genética, esse fator é um dos primordiais para o paciente realizar o teste de susceptibilidade à patologia em questão. Há possibilidade de realização de dois exames para confirmação da suspeita, sendo eles o exame de sangue genético molecular e o teste de contratura muscular para exposição ao halotano-cafeína, sendo o último o mais preciso (NUNES RBS, et al., 2020).

A sobrevida dos pacientes acometidos por essa desordem está diretamente relacionada ao conhecimento e atenção da equipe médica responsável, pois quanto mais cedo forem reconhecidos os sintomas e iniciada a reversão do quadro de hipertermia maligna, mais chances de evitar efeitos irreversíveis e restabelecer integralmente a saúde do paciente afetado (SCHNEIDERBANGER D, et al., 2014). 
Este trabalho visa revisar a gravidade da condição de hipertermia maligna, expondo a necessidade e as possíveis formas de diagnosticar pacientes susceptíveis antes de submetê-los a processos anestésicos, assim como abordar o manejo de tais pacientes evidenciando a importância de uma ação imediata e direta da equipe médica no enfrentamento de tal patologia.

\section{REVISÃO BIBLIOGRÁFICA}

\section{Histórico e definição da Hipertermia Maligna}

Em seu estudo, Costa WP, et al. (2017), descreve que o primeiro relato de HM aconteceu em 1960, quando um jovem apresentou o quadro após receber anestesia geral com halotano, oxigênio e óxido nitroso, somada ao fato de 10 de seus familiares irem a óbito após serem submetidos à anestesia geral, enquanto que um membro dessa mesma família foi submetido à anestesia espinhal e não enfrentou complicações, situações que permitiram sugerir que esses pacientes tinham herdado um gene dominante relacionado à $\mathrm{HM}$, a qual possui relação com anestésicos utilizados na anestesia geral.

Sabe-se que a HM é uma alteração genética hereditária e que já foram identificadas mutações em seis genes que estão associadas à HM. Entretanto, as mutações nesses genes estão presentes em cerca de $50 \%$ das famílias, sendo que nas demais famílias susceptíveis, o gene responsável ainda é desconhecido. Destaca-se também que existe uma variedade de tipos de mutações nesses genes, além de que as pessoas que apresentam mutações nos genes conhecidos, podem não desenvolver um episódio de HM na primeira vez em que forem expostas aos agentes desencadeadores (COSTA WP, et al., 2017).

\section{Epidemiologia}

A HM é uma desordem genética hereditária que afeta mais frequentemente o sexo masculino, possuindo uma relação de 2:1. Nota-se também uma maior incidência de HM em jovens, e embora seja estimado que a incidência de episódios quando se utiliza succinilcolina e agentes anestésicos voláteis halogenados esteja entre 1:10.000 e 1:250.000, a raridade do quadro associada à limitação de dados geram dificuldades para avaliar a incidência real de episódios. Concomitante a isso, ressalta-se que a incidência dos episódios de HM varia dependendo de fatores como raça, região, sexo e idade (LIMA RA, et al., 2020).

A prevalência de alterações genéticas ligadas ao quadro de HM possui uma proporção de 1:400 indivíduos sendo que cerca da metade dos pacientes que desenvolveram a HM tiveram uma ou mais exposições a agentes anestésicos desencadeadores antes e não apresentaram o quadro, situação que reforça a ideia segundo a qual um episódio de HM pode não ocorrer sempre que um indivíduo suscetível é exposto a um agente desencadeante (LIMA RA, et al., 2020). Já em relação à mortalidade, Kollmann-Camaiora A (2016), escreve uma redução nos números, pois a taxa de mortalidade inicial era de $60 \%$, passando para $10 \%$ com a utilização do manejo específico para o episódio de HM.

\section{Doenças associadas}

A partir da HM torna-se possível observar durante a crise sintomas e doenças associadas, dentre as quais destacam-se: doenças musculares, alterações osteoarticulares (escoliose, luxação crônica, pé torto congênito), os dismorfismos (fenda palatina, ptose palpebral, estrabismo) e miopatias (miopatia do alvo central), além de história de câimbras frequentes, criptorquidia, entre outros (AMARAL JLG, 2009).

O estrabismo, desordem miopática, predispõe o indivíduo ao desenvolvimento de HM. Ademais, se faz importante evidenciar algumas associações de doença neuromuscular identificáveis por meio do exame clínico neurológico (atrofia ou hipertrofia muscular), da eletroneuromiografia, do estudo anatomopatológico da biópsia muscular, do nível sérico de enzimas musculares (CPK está alterada em metade dos casos), da espectroscopia muscular ou de testes metabólicos musculares (AMARAL JLG, 2009).

Contudo, o diagnóstico diferencial da HM deve ser feito com condições que acarretem hipercarbia (problemas no circuito de ventilação, doenças respiratórias prévias, pneumoperitônio), hipermetabolismo (feocromocitoma, crise tireotóxica, intoxicação exógena por salicilatos, infecção) e/ou hipertermia (aquecimento iatrogênico do paciente, sepse) (LITMAN RS, 2005). 


\section{Diagnóstico}

Segundo Correia ACC (2012), o diagnóstico de HM é baseado em suas apresentações clínicas e laboratoriais, podendo ser manifestada imediatamente após a exposição a agentes desencadeantes ou em algumas horas após a interrupção da mesma. Após a suspeita, o indivíduo pode ser aconselhado a realizar exames para avaliar a suscetibilidade à $\mathrm{HM}$, por meio do teste de contratura muscular e testes genéticos moleculares, sendo a única maneira definitiva de descartá-la, um resultado do teste de contratura muscular negativo (DAGESTAD A e HERMANN M, 2017).

\section{Diagnóstico clínico}

A análise de indicadores clínicos prevê a probabilidade de um evento adverso ao anestésico, como a HM (DAGESTAD A e HERMANN M, 2017). São avaliados rigidez, lise muscular, acidose respiratória, aumento da temperatura, envolvimento cardíaco, história familiar e outros fatores (LIMA RA, et al., 2020). Os pacientes então recebem uma classificação, cujo objetivo não é orientar a conduta clínica, afinal mesmo pacientes com pontuações baixas, podem enfrentar episódios de HM (AMARAL JLG, et al, 2015).

As primeiras manifestações surgem com hipercapnia e taquicardia devido à produção elevada de $\mathrm{CO} 2 \mathrm{e}$ depois, condições clínicas de rigidez, rabdomiólise, acidose e hipercalemia. Sendo o aumento da temperatura corporalo sinal mais característico, podendo atingir valores superiores a $44^{\circ} \mathrm{C}$, levando a disfunções de órgãos vitais e coagulação intravascular disseminada (LIMA RA, et al., 2020).

A rabdomiólise induzida pela rápida contração muscular cursa com aumento da creatinina sérica e da mioglobinúria que se manifesta por colúria, que se não for tratada a tempo, progride rapidamente à insuficiência renal aguda. Ademais, quadros de hipercalemias severas podem ser observados, podendo desencadear uma fibrilação ventricular (OJEDA D, 2017).

De acordo com Correia ACC (2012), entre 12-24 horas de evolução, é encontrado um aumento dos níveis plasmáticos da enzima creatinoquinase (CPK). No entanto, a confirmação da suscetibilidade se dá, de fato, por meio do teste de contratura ao halotano e à cafeína, indicado apenas depois de três meses decorridos da crise.

\section{Capnografia}

A HM é estado hipermetabólicoque causa um aumento imediato na produção de CO2. É importante a detecção precoce, pois hipercalemia, arritmias, rabdomiólise, mioglobinemia/mioglobinúria e coagulação intravascular disseminada estão ocorrendo em paralelo (OJEDA D, 2017). As análises são feitas a partir do gás expirado (EtCO2), sangue venoso (PvCO2) e sangue arterial (PaCO2). Valores acima de $5 \mathrm{mmHg}$ merecem pronta investigação (AMARAL JLG, et al., 2015).

\section{Biópsia muscular}

Werner Kalow e Beverly Britt descobriram em 1970, a partir de amostras musculares de pacientes que apresentaram um episódio de HM, uma resposta contrátil exagerada em relação à estimulação da cafeína. $\mathrm{A}$ partir disso, foi desenvolvida a base do teste de contratura in vitro com halotano-cafeína, sendo hoje padrão ouro para confirmar a suscetibilidade (OJEDA D, 2017).

Esse teste avalia a anormalidade do metabolismo do cálcio intracelular, não indicando, necessariamente, a presença de uma mutação genética. Por outro lado, um teste positivo indica anormalidade da fibra muscular que pode, com o tempo, induzir alterações da morfologia da fibra muscular elou até uma miopatia clinicamente evidente (COSTA WP, et al., 2017).

Para sua realização, se faz necessário uma biópsia com extração de dois gramas de músculo, geralmente da coxa, que possui usabilidade de apenas algumas horas (LIMA RA, et al, 2020). Essa amostra requer hospitalização e deve ser colhida em momentos fora da crise, pois em momentos de crise pode ser considerado irresponsível, tendo uma sensibilidade próxima à 100\% (AMARAL JLG, et al, 2015).

O diagnóstico é considerado positivo quando há uma contração $\geq 0,5 \mathrm{~g}$ para o halotano $3 \% \mathrm{e} \geq 0,3 \mathrm{~g}$ para $2 \mathrm{mM}$ de cafeína (CORREIA ACC, et al., 2012). O teste de contratura deve ser considerado para todos os 
pacientes em risco de $\mathrm{HM}$, como aqueles com antecedente familiar ou pessoal, sendo o resultado negativo a única maneira de provar a não suscetibilidade à HM (LIMA RA, et al., 2020).

\section{Teste genético}

Em 1990, foi identificado o lócus cromossômico em que residia a mutação responsável pela HM. O gene RYR1 é responsável por codificar o canal de transporte de cálcio do músculo esquelético. Após isso, outras mutações desse gene associadas à HM foram identificadas. Entretanto, apenas $50-70 \%$ dos casos de HM estão associados a uma mutação do gene mencionado (DAGOBERTO OJEDA D, 2017). A partir do momento em que é feito o diagnóstico de HM, o paciente pode ser submetido ao teste genético, e se apresentar resultados positivos, a família pode testar também (LIMA RA, et al., 2020).

Seis genes que podem apresentar mutações que predisponham os indivíduos à HM são descritos pela literatura, sendo expressos em cerca de metade das famílias que participaram do estudo (COSTA WP, et al., 2017). Essa grande variabilidade de genótipos dificulta o diagnóstico da doença, tomando como base apenas o estudo molecular, uma vez que um resultado negativo do teste genético, não descarta a susceptibilidade à HM. Ademais, uma mutação no gene RYR1 não aponta automaticamente susceptibilidade à HM (DAGESTAD A e HERMANN M, 2017).

A análise dos resultados se dá da seguinte forma: caso algum familiar teste positivo para essa mutação, eles serão considerados suscetíveis à HM. Assim, membros da família que apresentarem resultado negativo, ainda devem ser tratados como possíveis suscetíveis à $\mathrm{HM}$, sendo encaminhados a um teste de contratura muscular (LIMA RA, et al., 2020).

Além disso, mesmo que o indivíduo apresente uma mutação genética predisponente à HM, não significa que essa disfunção será expressa durante exposição prévia a um agente desencadeante, dada a sua penetrância incompleta inerente (COSTA WP, et al., 2017).

\section{Tratamento da crise}

O sucesso do tratamento da hipertermia maligna é dependente de uma rápida identificação da crise e de uma intervenção precoce, principalmente com o uso adequado do antídoto dantrolene - fármaco obrigatório em locais que apresente utilização de compostos halogenados e succinilcolina, essencial para a reversão desse quadro (LITMAN RS, et al., 2014; SILVA HCA, et al., 2019; COSTA WP, et al., 2017). A introdução deste medicamento no Brasil, registrado pela ANVISA apenas em 1997 possibilitou que a taxa de mortalidade de hipertermia maligna caísse para menos de $5 \%$, quando associado ao monitoramento intra-operatório apropriado (HELGA CAS, et al., 2019; IN J, et al, 2017; WEL B, et al., 2018).

O dantrolene, derivado da hidantoína, atua interrompendo as contrações musculares e, com isso, diminuindo a liberação excessiva de cálcio, o que por fim, reverte o quadro hipermetabólico muscular (DAGESTAD A e HERMANN M, 2017). Sua administração é autorizada a partir do momento em que se percebem os sinais clínicos da crise, que apesar de serem altamente variáveis, devem ser criteriosamente observados durante qualquer procedimento com uso de anestésicos desencadeantes (SCHNEIDERBANGER D, et al., 2014; COSTA WP, et al., 2017).

\section{Identificação da crise}

Nos estudos de Costa WP, et al. (2017), demonstrou-se que $96 \%$ das crises de hipertermia maligna apresentam-se inicialmente com instabilidade cardiovascular, podendo evoluir para extrassístoles, arritmias ventriculares e parada cardíaca perioperatória. Ademais, taquicardias sinusais inespecíficas poderiam ser interpretadas como uso incorreto do anestésico, o que frequentemente atrasa o diagnóstico de hipertermia maligna (SCHNEIDERBANGER D, et al., 2014).

Nesses casos, o uso do dantrolene é suficiente para reverter quadros arrítmicos, entretanto, caso opte-se por utilizar drogas antiarrítmicas, deve-se atentar à restrição aos bloqueadores de canais de cálcio, associados a hiperpotassemia e colapso circulatório nesses cenários. Sendo assim, os principais sinais iniciais apontados foram taquicardia e aumento repentino da EtCO2 (COSTA WP, et al., 2017; SCHNEIDERBANGER D, et al., 2014; WEL B, et al., 2018). 
É importante destacar que, apesar da maioria dos sinais e sintomas se apresentarem durante $\mathrm{o}$ ato operatório, $20 \%$ se manifestam até cerca de uma hora após a interrupção do anestésico. Como exemplo, a elevação da temperatura denominada hipertermia, tem achados controversos na literatura. Elevações acima de $1,8^{\circ} \mathrm{C}$ a cada cinco minutos são achados clínicos precoces em $65 \%$ dos pacientes em um estudo publicado em 2017 (COSTA WP, et al, 2017). Em contrapartida, segundo Schneiderbanger D (2014), um aumento rápido da temperatura (até $38,8^{\circ} \mathrm{C}$ ) é interpretado como um sinal tardio.

Por fim, outras alterações mais generalizadas também foram notificadas, como: hipoglicemia intensa, aumento do lactato sérico, hipercalemia, espasmo isolado do masseter, rigidez muscular em $50 \%$ a $80 \%$ dos pacientes, aumento da CPK (ocorre em 50\% dos casos nas primeiras 24 horas do início da crise), acidose mista, mioglobinúria, colúria, insuficiência renal aguda secundária à rabdomiólise, alteração de enzimas hepáticas, coagulação intravascular disseminada, insuficiência cardíaca congestiva, isquemia e síndrome compartimental secundária ao edema muscular, podendo chegar a uma falha e colapso circulatório de múltiplos órgãos em último caso (SCHNEIDERBANGER D, et al., 2014; COSTA WP, et al., 2017 ).

\section{Manejo da crise}

Para um bom prognóstico, a intervenção de uma crise de hipertermia maligna deve ser iniciada dentro de 3-7 minutos a partir da percepção dos sinais clínicos citados anteriormente, uma vez que o atraso no início da terapia está associada a um aumento da morbimortalidade a cada 30 minutos após o início da crise (SILVA HCA, et al., 2019; COSTA WP, et al., 2017; DAGESTAD A e HERMANN M, 2017).

Os primeiros passos são a interrupção dos agentes anestésicos desencadeantes, a oferta de oxigênio a $100 \%$ no fluxo máximo e a administração imediata do dantrolene. Além da troca dos circuitos e aparelhagem anestésica, estes devem ser lavados com alto fluxo de oxigênio, em média, por 15 minutos (COSTA WP, et al., 2017).

A cirurgia deve ser interrompida o mais rápido possível, porém, se ainda houver necessidade anestésica até a estabilização do paciente, esta deve ser continuada com opióides intravenosos, sedativos, e se necessário, relaxantes musculares não despolarizantes (SCHNEIDERBANGER D, et al., 2014).

$\mathrm{O}$ uso do dantrolene pode ser dividido em duas fases. Na fase inicial, utiliza-se $2 \mathrm{mg} / \mathrm{kg}$ ou $2,5 \mathrm{mg} / \mathrm{kg}$ de dantrolene sódico diluído em bolus, podendo ser repetido a cada cinco minutos por até quatro vezes, até se obter estabilização cardiorrespiratória. Se mais doses do dantrolene forem exigidas, deve-se repensar o diagnóstico (SCHNEIDERBANGER D, et al., 2014; SILVA HCA, et al., 2019; DA COSTA WP, et al., 2017). Para a segunda fase, de manutenção, a dose é diminuída para $1 \mathrm{mg} / \mathrm{kg}$ a cada seis horas por até 48 horas (COSTA WP, et al., 2017).

Simultaneamente ao dantrolene, deve ser feito controle da temperatura corporal, se acima de $39^{\circ} \mathrm{C}$, a partir do resfriamento de superfícies corporais (uso de compressas geladas ou gelo e infusão de fluídos resfriados até temperatura atingir $38,5^{\circ} \mathrm{C}$ ), tratamento de possíveis complicações (acidose mista, hipercalemia, arritmias, choque, disfunções renais, coagulação intravascular disseminada) e manutenção da diurese acima de $1 \mathrm{ml} / \mathrm{kg} / \mathrm{h}$ para proteção renal (COSTA WP, et al., 2017).

Apesar de alguns estudos indicarem o uso profilático de dantrolene em pacientes suscetíveis, literaturas atuais contradizem esse manejo, tanto a administração via oral quanto a intravenosa são consideradas ultrapassadas (COSTA WP, et al., 2017). Os efeitos colaterais do dantrolenepodem se apresentar através de fraqueza muscular transitória em até 48 horas e de flebite local (COSTA WP, et al., 2017).

Ademais, Schneiderbanger D (2014), apontou problemas respiratórios por tempo prolongado, necrose tecidual após extravasamento acidental da injeção, náusea, vômitos, cefaléia e tontura. Por último, Dagestad A e Hermann M (2017), relataram complicações como dor, eritema e edema que podem evoluir para necrose tecidual devido aos seus altos níveis de $\mathrm{pH}$.

Após a estabilização do paciente, este deve ser transferido para uma unidade de terapia intensiva, onde será observado por 24 horas, no mínimo (AMARAL JLG, et al., 2005). Essa medida se torna necessária, visto que evidências destacam que durante esse período existe um risco de $20 \%$ a $25 \%$ de recorrência dos 
sintomas (COSTA WP, et al., 2017; DAGESTAD A e HERMANN M, 2017). Na alta do paciente, deve ser enfatizada a necessidade de evitar anestésicos desencadeantes e de informar os membros familiares acerca de uma possível investigação de hipertermia maligna, devido a sua característica genética.

\section{CONSIDERAÇÕES FINAIS}

Acerca da HM, conclui-se que é uma doença autossômica dominante, que se expressa através do uso de anestésicos inalatórios halogenados e/ou pela succinilcolina. Devido às manifestações clínicas, é imprescindível a identificação e o manejo precoces pela equipe médica. Logo, a confirmação do diagnóstico pode ser realizada através do teste de contratura in vitro com halotano-cafeína ou teste genético, entretanto, apesar da baixa incidência, é importante a capacitação de toda a equipe profissional para uma rápida intervenção e consequente redução da mortalidade.

\section{REFERÊNCIAS}

1. AMARAL JLG, et al. Hipertermia Maligna Anestésica. Revista Neurociências, 2005; 13(3): 39-46.

2. CORREIA ACC, et al. Hipertermia Maligna: Aspectos Moleculares e Clínicos. Revista Brasileira de Anestesiologia, 2012; 62(6): 820-837.

3. CORVETTO MA, et al. Hipertermia maligna: ¿cómo estar preparados? Revista chilena de cirugía, 2013; 65(3): 279284.

4. COSTA WP, et al. Hipertermia maligna: revisando aspectos importantes. Rev. Med Minas Gerais., Belo Horizonte, 2017; 27(2): S67-S73.

5. DAGESTAD A, HERMANN M. Keeping Cool When Things Heat Up During a Malignant Hyperthermia Crisis. NursWomens Health, 2017; 21(5): 338-347.

6. AMARAL JLG, et al. Hipertermia Maligna. Projetos Diretrizes. São Paulo: AMB/CFM, 2009.

7. HOPKINS PM, et al. European Malignant Hyperthermia Group guidelines for investigation of malignant hyperthermia susceptibility. British Journal of Anaesthesia, 2015; 115(4): 531-9.

8. JUNYONG IN, et al. Incidence of malignant hyperthermia in patients undergoing general anestesia. Medicine, 2017; 96(49): e9115.

9. KOLLMANN-CAMAIORA A, et al. Protocolo clínico asistencial de manejo de la hipertermia maligna. Rev. Esp. Anestesiol Reanim, 2016; 64(1): 32-40.

10. LITMAN RS, ROSENBERG H. Malignant Hyperthermia. Update on Susceptibility Testing. Am Med Assoc, 2005

11. LIMA RA, et al. Hipertermia maligna: uma revisão de literatura. Brazilian Journal Health Review, 2020; 3(2): 24752489.

12. LITMAN RS, et al. Malignant Hyperthermia in the Ambulatory Surgery Center. How Should We Prepare? Anesthesiology, 2014; 120: 1306-1308.

13. NUNES RBS, et al. Hipertermia maligna: uma revisão de literatura. Brazilian Journal Health Review, 2020; 3(2): 24752489.

14. OJEDA D. Hipertermia maligna Aspectos históricos. Revista Chilena de Anestesia, 2017; 46: $19-24$.

15. SCHNEIDERBANGER D et al. Management of malignant hyperthermia: diagnosis and treatment. Dove Medical Press, 2014; 10: 355-362.

16. SILVA HCA, et al. Anestesia durante biópsia muscular para teste de suscetibilidade à hipertermia maligna. Revista Brasileira de Anestesiologia, 2019; 69 (4): 335-341.

17. SILVA HCA, et al. Perfil dos relatos de suscetibilidade à hipertermia maligna confirmados com teste de contratura muscular no Brasil. Revista Brasileira de Anestesiologia, 2019; 69(2): 152-159.

18. SIMOES CM, et al. Estamos preparados para diagnosticar e conduzir um episódio de hipertermia maligna? Revista Brasileira de Anestesiologia, 2003; 53(2): 248-257.

19. VASCONCELOS JVRM, et al. Hipertermia maligna em paciente submetida à correção de gigantomastia: relato de caso. Revista Brasileira de Cirurgia Plástica, 2007; 22(2): 126-130.

20. WEL B, CLAEYS KG. Malignant hyperthermia: still an issue for neuromuscular diseases? Current Opinion in Neurology, 2018; 31(5): 628-634. 